REVIEW

This paper is dedicated to the $70^{\text {th }}$ anniversary of the founding of Physiologia Bohemoslovaca (currently Physiological Research)

\title{
Puncture Vine (Tribulus Terrestris L.) in Control of Health and Reproduction
}

\author{
Alexander V. SIROTKIN ${ }^{1}$, Adriana KOLESAROVA ${ }^{2}$ \\ ${ }^{1}$ Constantine the Philosopher University in Nitra, Nitra, Slovak Republic, ${ }^{2}$ Slovak University of \\ Agriculture in Nitra, Nitra, Slovak Republic
}

Received April 23, 2021

Accepted June 29, 2021

\section{Summary}

Tribulus terrestris, L. (puncture vine) have been used as a folk medicine for five thousands of years, but its targets, effects, their mechanisms and application requires further studies. This paper reviews the provenance, constituents and properties of Tribulus terrestris, L., its general physiological and health effects, as well as the currently available knowledge concerning its influence on male and female reproductive processes and their dysfunctions. Analysis of the available publications demonstrated the influence of Tribulus terrestris on a wide spectrum of targets and physiological processe and disorders. In particular, Tribulus terrestris can be a stimulator of male and female reproductive processes at the level of central nervous system, sexual behaviour, pituitary and gonadal hormones and their receptors, gonadal functions (including ovarian follicullogenesis and spermatogenesis), improvement of the quality and quantity of gametes (at least of sperm) and fecundity. This ability of puncture vine is applicable for the improvement of man's sexual desire and sperm quality in vivo and in vitro, as well as of women's libido, activation of women's reproductive organs, fecundity, and treatment of infertility, especially that related to the polycystic ovarian syndrome.

\section{Key words}

Nutrition • Health • Testis • Ovary • Hormone • Signalling

\section{Corresponding author}

A. V. Sirotkin, Dept. Zoology and Anthropology, Constantine the Philosopher University in Nitra, Tr. A. Hlinku 1, 94974 Nitra, Slovak Republic. E-mail: asirotkin@ukf.sk

\section{Introduction}

Puncture vine (Tribulus terrestris L.) is a popular medicinal plant, which is considered as a traditional stimulator of masculine sexual desire. The available reviews concerning this plant do not reflect the recent information (Ukani et al. 1997, Chhatre et al. 2014, Shahid et al. 2016, Zhu et al. 2017), or they are focused on puncture vine's influence and use in man's reproduction (Neychev and Mitev, 2016, GamalEl Din, 2018, Sanagoo et al. 2019, Santos et al. 2019, Abarikwu et al. 2020). Current reviews concerning Tribulus terrestris effect on female reproduction, as well as on non-reproductive physiological and therapeutical actions of puncture vine, are practically absent in the available literature. This review summarizes briefly the available information concerning Tribulus terrestris provenance, constituents, properties, its action, and application in the control and treatment of male and female reproductive and non-reproductive processes and their disorders.

\section{Provenance and properties}

The genus Tribulus, belonging to the family Zygophyllaceae, comprises about 20 species in the world, of which Tribulus terrestris, L. is the most common and popular as medicinal and food herb of this genus (Ukani et al. 1997, Chhatre et al. 2014, Parham et al. 2020).

The phytochemical study of Tribulus terrestris revealed the presence of steroidal saponins, flavonoids,

PHYSIOLOGICAL RESEARCH • ISSN 1802-9973 (online) - an open access article under the CC BY-NC-ND 4.0 license (c) 2021 Institute of Physiology of the Czech Academy of Sciences, Prague, Czech Republic Fax +420 241062 164, e-mail: physres@fgu.cas.cz, www.biomed.cas.cz/physiolres 
flavanol glycosides, alkaloids, and tannins (Chatre et al. 2014, Saiyed et al. 2016, Shahid et al. 2016, Zhu et al. 2017). The saponins included furostanol and spirostanol saponins of tigogenin, neotigogenin, gitogenin, neogitogenin, hecogenin, neohecogenin, diosgenin, chlorogenin, ruscogenin, and sarsasapogenin. In addition, four sulfated saponins of tigogenin and diosgenin type were also isolated. Saponins show variation in type, structure and composition of their aglycone moiety and oligosaccharide chains, but many saponins have surface active properties, as well as ability to reduce the risk of many chronic diseases and to exerts cytotoxic effects on cancer (Singh et al. 2017) (see below). Tribulus terrestris is characterized by high concentration and number (more than 18) kinds of flavonoids. The main flavonoids isolated from leaves and fruits of puncture vine were kaempferol, kaempferol-3-glucoside, kaempferol-3rutinoside, and tribuloside [kaempferol-3- $\beta-\mathrm{d}-\left(6^{\prime \prime}-p-\right.$ coumaroyl) glucoside], caffeoyl derivatives, quercetin glycosides, including rutin and kaempferol glycosides (quercetin 3-O-rutinoside, quercetin 3-O-glycoside and kaempferol 3-O-glycoside) with anti-oxidant and phytoestrogenic properties (Chhatre et al. 2014, Kuchakulla et al. 2020, Verma et al. 2020). The plant also contains a mixture of beta-carboline alkaloids: harmane, norharmane, tetrahydroharmane, harmine, harmaline, harmol, harmalol, ruin and dihydroruin (Al-Bayati et al. 2008). The plant size, number of seeds, and the contents of furostanol saponins are very variable in dependance on the location and conditions of plant growth (Šalamon et al. 2006). Therefore, Tribulus terrestris contains a number of phytochemicals with potential biological activity.

\section{Physiological actions}

The fruits and roots of Tribulus terrestris, alone or in combination with other medicinal plants, have been used as a folk medicine for five thousands of years in various Asiatic countries (Cchatre et al. 2014, Shahid et al. 2016, Zhu et al. 2017, Kamrani et al. 2019). In the ayurvedic medicine its application is recommended for the treatment of urinary affection, urinary calculi, polyuria, dyspnoea, cough, piles dysuria, heart disease and as a gastric stimulant (Ukani et al. 1997). In native Chinese medicine, the leaves of Tribulus terrestris are used for treatment of stomach problems, bladder stones, male reproductive disorders (Kumari and Singh 2015), and ocular diseases (Yuan et al. 2020).
Some of the Tribulus terrestris effects listed above were confirmed by modern Western medicine. The current scientific literature describes the following physiological, protective and therapeutical activities of puncture vine (Chhatre et al. 2014, Shahid et al. 2016): diuretic, antiurolithic, immunomodulatory, antidiabetic, hypolipidemic, cardiotonic, on central nervous system, hepatoprotective, anti-inflammatory, analgesic, antispasmodic, antibacterial, anthelmintic, larvicidal, and anticariogenic and anticancer activities (Chhatre et al. 2014, Parham et al. 2020, Verma et al. 2020). It is noteworthy that the toxic influence of Tribulus on cancer cells was more pronounced than that on healthy fibroblasts, suggesting the possibility of selective application of this plant against cells with malignant transformation (Neychev et al. 2007). In-vitro studies showed the protective effect of puncture vine against ocular retina injury (Yuan et al. 2020). Tribulus phytochemicals can be a promising replacement for routine antibiotics and antivirotics including anti-HIV treatment (Shaheen et al. 2019, Parham et al. 2020). Animal studies revealed its applicability for protection against bone loss induced by estrogen deficit during agerelated osteoporosis (Marques et al. 2019). Clinical studies indicated its applicability for weight loss (Salgado et al. 2017), prevention and treatment of hypertenzia, coronary hearth disease, cerebral arteriosclerosis, myocardial infarction, thrombosis (Verma et al. 2021), urinary tract infections, urolithiasis, dysmenorrhea, edema, hypertension, hypercholesterolemia (Shahid et al. 2016, Zhu et al. 2017, Shaheen et al. 2019) and physical fitness and muscular performance (Al-Bayati et al. 2008, Ma et al. 2017, Wu et al. 2017, Sellami et al. 2018). On the other hand, some studies did not reveal Tribulus terrestris action on physical performance in athletes (Pokrywka et al. 2014), sportsmen's muscle mass (Ma et al. 2017), body composition and muscular endurance in resistance-trained men (Sellami et al. 2018).

The variability in the targets of Tribulus terrestris can be due to the variability in its biological active constitutients. The constituents of Tribulus terrestris, which are responsible for the particular effects of this plant, are however not fully determined. One group of possible puncture vine constituents could be phytoestrogenic saponins diosgenin, dioscine and protodioscin. Their anti-oxidant, anti-inflammatory, antidiabetic, anti-cancer, cardioprotective and neuroprotective properties, as well as the ability to promote libido and physical fitness are similar to 
properties of Tribulus terrestris (Parama et al. 2020). The next candidate constituent of puncture vine could be phytosterols, in particular beta-sistosterols, which, like puncture vine, can be beneficial for the prostate function, the urinary system, and the cardiovascular system (Sellami et al. 2018). Nevertheless, the only the similarity in action of Tribulus and its molecules cannot be direct evidence, that just these molecules and their amounts are defining the action of this plant and explain the variability in its effect.

Some evidence indicates the adverse effect of puncture vine overconsumption: it can induce sleeping disorder, burnout and fatigue, hypertension, high heart rate (Sellami et al. 2018), photosensitisation and the resulted injury in both humans and animals (Chen et al. 2019). One case of intoxication with Tribulus has been reported (Pokrywka et al. 2014). On the other hand, clinical trials did not report serious adverse events induced in women by long Tribulus terrestris treatment (Martimbianco et al. 2020).

Therefore, Tribulus terrestris can target a number of variable physiological processes. Therefore, it can be a promising tool for treatment of a wide array of illnesses.

\section{Mechanisms of action}

The number of processes affected by puncture vine indicates the possible variability in its mechanisms of action, which are sometimes not properly discovered. Nevertheless, the mediators of plant action on some selected processes and illnesses have been currently outlined.

Some Tribulus effects could be mediated by changes in hormones, cytokines and growth factors release, binding and reception. For example, in rats undergoing exercise Tribulus terrestris extract promoted muscle gain and physical performance, which was associated with an increase in plasma level of both IGF-I and its receptor (Wu et al. 2017). In boxers, the ability of Tribulus terrestris to alleviate muscle damage and to promote anaerobic performance was associated with a decrease in plasma insulin-like growth factor binding protein-3 (IGFBP-3), but not in its target - IGF-I (Ma et al. 2017). These reports indicate, that physical performance (and maybe activity, proliferation and reparation of cells other than myocytes) could be promoted in puncture vine by two ways - via reduction in IGFBP-3, which binds/inactivates the IGF-I and via up- regulation of IGF-I receptors. Under the influence of puncture vine, the increased amount of free IGF-I binds and activates increased the amounts of IGF-I receptors.

The bone-protective effect of Tribulus terrestris observed in rats is explained by its ability to increase bone mineral density. This activity may be at least partially attributable to an increase in the serum level of dehydroepiandrosterone (but not of testosteron or estradiol) and a $\mathrm{Ca}^{2+}$-sparing effect (Marques et al. 2019).

The anti-inflammatory action of puncture vine can be mediated by prostaglandin. For example, addition of Tribulus terrestris to mouse macrophages inhibited their cyclooxygenase 2 (COX-2), an enzyme promoting prostaglandin E2, which is in turn involved in promotion of inflammation. It suggests that prostaglandin E can be a mediator of anti-inflammatory action of Tribulus terrestris (Hong et al. 2002).

The anti-inflammatory action of Tribulus can be mediated also by the intracellular promoter of inflammation - transcription factor nuclear factor kappaB (NF-kB). For example, Tribulus can protect on rat brain from inflammation induced by formalin and carrageenan by down-regulation of NF-kB (Ranjithkumar et al. 2019). On the contrary, derivatives of Tribulus terrestris alcaloids can destroy cancer cells (Jurkat E6-1) via up-regulation of this transcription factor (Basaiyye $e t$ al. 2017). Gautam and Ramanathan (2019) demonstrated that the ability to puncture vine saponins to prevent brain inflammation and to relieve pain can be attributed to attenuation of both pro-inflammatory cytokines, Tumor Necrosis Factor Alpha (TNF- $\alpha$ ), Interleukin 1 beta (IL-1 $\beta$ ), and interleukin 6 (IL-6) and brain neurotransmitters, glutamate and aspartate.

Moreover, the neuroprotective action of Tribulus on rat brain was associated with activation of antiapoptotic and pro-proliferating MAP kinase pathway (Ranjithkumar et al. 2019, Reshma et al. 2019) and neuronal survival pathway (BDNF), by changes in apoptosis-related protein kinases JNK, GSK3 $\beta / \beta$ catenin (Ranjithkumar et al. 2019) and activation of promoters of apoptosis caspase-3 and AIF (Ranjithkumar et al. 2019, Yuan et al. 2020). The toxic effect of Tribulus on human fibroblasts was also associated with suppression of their proliferation, activation of their apoptosis and changes in cellular polyamines' homeostasis (Neychev et al. 2007).

A number of Tribulus phytochemicals including flavonoid, tannin, and phenolic acids have antioxidant properties, which can prevent oxidative stress, inflammation, apoptosis and the development of 
a number of illnesses mentioned above (Parham et al. 2020). For example, Tribulus terrestris can protect ocular retina cells from oxidative stress-induced injury and apoptosis and increase their resistance and viability through activating numerous antioxidant enzymes and PI3K/Akt-Nrf2 signaling pathway (Yuan et al. 2020).

Studies on rats indicated that the antihypertensive effect of puncture vine can be due to its action on membrane hyperpolarization and relaxation of arterial smooth muscle, to boost up the discharge of nitric oxide from the nitrergic nerve endings and endothelium and/or by inhibitory action on angiotensin converting enzyme (Kamrani et al. 2019, Verma et al. 2020).

The ability of Tribuus terrestris to relieve painful urination or dysuria, hematuria, urinary urgency, burning micturition, frequent urination, nausea, and vomiting can be explained by its bacteriostatic and bacteriocidal action on a wide spectrum of urogenital bacteria, viruses and fungi (Al-Bayati et al. 2008, Shaheen et al. 2019, Parham et al. 2020). This action could be explained by the ability of Tribulus saponins to induce lysis of bacterial membranes (Al-Bayati et al. 2008).

These observations demonstrate the variablity of the mechanisms mediated by Tribulus terrestris on various target organs and processes (and sometimes on the same target).

\section{Effect on male reproductive process}

The best-known feature and area of Tribulus terrestris application in folk and official medicine is its ability to treat the loss of libido and infertility in animals (Haghmorad et al. 2019) and man (Sahin et al. 2016, Shahid et al. 2016, GamalEl Din 2019). It is proposed that saponins like dioscine, diosgenin, and the protodioscin can have beneficial effects on libido, whilst phytosterols, in particular beta-sistosterols, can be beneficial for the prostate function, and, therefore, for male fecundity (Sellami et al. 2018).

Analysis of phytochemical and pharmacological studies on animals and humans revealed an important role of Tribulus in treating erectile dysfunction and sexual desire problems (Neychev and Mitev, 2016) and fertility (Kumari et al. 2018). On the other hand, the performed clinical studies provided controversial and inconclusive results concerning the applicability of this plant for treatment of male infertility. Such results could be due to clinical trials, which were imperfect from the viewpoint of methodology and patient number, as well as the differences in causes of male infertility (Gamal El Din 2018).

In contrast to Tribulus terrestris action on libido and erectile function, the ability of this plant to improve on male sperm parameters, namely number, motility and morphology, has been demonstrated in the majority of performed clinical studies (Roaiah et al. 2017, Salgado et al. 2017, Sanagoo et al. 2019). Animal and in-vitro studies also demonstrated that Tribulus terrestris can increase sperm quantity, quality in rats (Martino-Andrade et al. 2010, Kumari and Singh 2015, Sahin et al. 2016, de Souza et al. 2019, Salahshoor et al. 2020), rams (Kistanova et al. 2005), livestocks (Clément et al. 2012) and humans (Asadmobini et al. 2017, Khaleghi et al. 2017). In rams Tribulus terrestris increased fertility (Kistanova et al. 2005).

The positive influence of Tribulus on sperm has been associated with signs of activation of male reproductive organs. At least, Tribulus terrestris increased mouse testis weight and recovered the spermatogenic cycle (Kumari and Singh, 2015). Puncture vine enhanced the number of Leydig, spermatogonia and spermatid cells in rat testis (Haghmorad et al. 2019). Similarly, protodioscin, the main phytochemical agent of the Tribulus, can promote proliferation of Sertoli and germ cell proliferation, which promotes the growth and function of seminiferous tubules in men (Salgado et al. 2017). On the other hand, no influence of Tribulus terrestris extract on weight and histostructure of rat prostate, seminal vesicles, and height of germinal layer of seminiferous tubule has been found (Martino-Andrade et al. 2010, Sahin et al. 2016, Salahshoor et al. 2020).

Therefore, the ability of Tribulus terrestris to improve sperm characteristics and therefore male fertility can be evident. On the other hand, Tribulus action on the state of reproductive organs has been examined only in rats, whilst the obtained results were sometimes contradictory. Tribulus terrestris applicability to treat psychological and physical impotence remains an open question too, which should be addressed by strong clinical studies.

\section{Mechanisms of effects on male reproduction}

Results of the basic studies indicate that Tribulus terrestris can affect male reproductive processes via the same extra- and intracellular mediators as the nonreproductive processes (see above). 
Some (but not all) studies indicated that puncture vine can affect male reproductive processes through the up-regulation of release of reproductive hormones gonadotropins and androgens. Treatment of rats with Tribulus terrestris increased level of LH (but not FSH) and testosterone in their plasma (Ghosian Moghaddam et al. 2013, Haghmorad et al. 2019, Salahshoor et al. 2020). Sahin et al. (2016) observed the stimulatory action of Tribulus extract on rat plasma testosterone, but not LH or FSH. Some studies showed the ability of Tribulus terrestris to increase dihydrotestosterone (Selgado et al. 2017) and testosterone (Sahin et al. 2016, Roaiah et al. 2017, Sellami et al. 2018, GamalEl Din 2019) levels in men's plasma. Other studies however did not detect Tribulus terrestris influence on androgen release in rat (Martino-Andriade et al. 2010, Ghosian Moghaddam et al. 2013) or humans (Pokrywka et al. 2014, Neychev and Mitev, 2016, Ma et al. 2017, Santos et al. 2019, Kuchakulla et al. 2021), although the puncture vine influence on libido and fecundity occured. These observations suggest that „empirical evidence to support the hypothesis that this desirable effects are due to androgen enhancing properties of Tribulus terrestris is, at best, inconclusive“ (Neychev and Mitev, 2016), and androgens are not (or not always) mediators of male reproduction-stimulating activity of Tribulus terrestris.

More probable appears the hypothesis explaining Tribulus terrestris effect on brain structures. At least, treatments with puncture vine extract promoted nicotinamide adenine dinucleotide phosphate-diaphorase activity and androgen receptor immunoreactivity in rat brain (Gauthman and Adaikan, 2005). These structures could be central mediators of puncture vine action on sexual behavior. Therefore, this plant could promote androgen-dependent events not (or not only) via androgen production, but also through androgen reception and effects in the brain.

Puncture vine can improve sperm production through activation of proliferation of testicular cells and spermatogenesis, which has been reported after Tribulus terrestris or its constituent protodioscin in mice (Kumari and Singh, 2015), rat (Haghmorad et al. 2019) and man (Salgado et al. 2017).

Tribulus terrestris-induced stimulation of rat reproductive behavior and testosterone release were associated with reduction of transcription factor NF- $\mathrm{KB}$ and increased the levels of NF-E2-related factor 2 ( $\mathrm{Nrf} 2)$ and heme-oxygenase-1 (HO-1) accumulation in their male reproductive organs (Sahin et al. 2016). It suggests that these signaling substances could be intracellular mediators of puncture vine on libido or androgen release. Furthermore, there is emerging compelling evidence from experimental studies in animals for possible endothelium and nitric oxide-dependent mechanisms underlying tribulus terrestris aphrodisiac and pro-erectile activities (Neychev and Mitev, 2016). It is still to be examined whether intracellular signaling mechanisms mediate puncture vine action on human male reproductive processes.

The stimulatory action of Tribulus terrestris on male sperm quality could be due to antioxidative properties of some plant molecules (see above). Addition of antioxidants usually increases sperm quality. Tribulus terrestris increased the concentration of antioxidative enzymes and the anti-oxidant activity in mice testis, as well as the sperm resistance to oxidative stress (Kumari and Singh, 2015, Salahshoor et al. 2020). Clément et al (2012) explained the benefits of Tribulus terrestris extract for livestock sperm by antioxidant properties of puncture vine constituents.

Therefore, Tribulus terrestris can improve various male reproductive parameters via brain structures and through direct action on the testis and sperm. This effect can be mediated by stimulatory action of puncture vine action on ovarian gonadotropins, androgens, androgen receptors, several intracellular signaling pathways and by the ability of Tribulus terrestris to scavenger reactive oxygen species. The possible targets and mechanisms of Tribulus action on male and female reproductive system are present in Fig.1.

\section{Effects on female reproductive processes}

The effect of Tribulus terrestris on female reproductive processes and its application for treatment of female reproductive disorders are studied much less than this plant in relation to male reproduction. Nevertheless, the few available publications indicate the influence of puncture vine on female reproductive hormones, behavior, ovarian, oviductal and uterus state, ovarian cycle, ovulation and fecundity.

Clinical studies demonstrated the ability of Tribulus terrestris to promote libido and other signs of sexual behavior and to prevent their decline in pre- and postmenopausal women (Mazaro-Costa et al. 2010, Martimbianco et al. 2020).

Abadieva et al. (2016) reported that feeding with Tribulus terrestris altered the expression of bone 
morphogenetic protein (BMP) 15 and growth differentiation factor (GDF) 9 in rabbit ovarian structures. Tribulus terrestris caused a decrease in the BMP15 mRNA level in the oocytes and an increase in the cumulus cells. The GDF9 mRNA level increased significantly in both oocytes and cumulus cells.

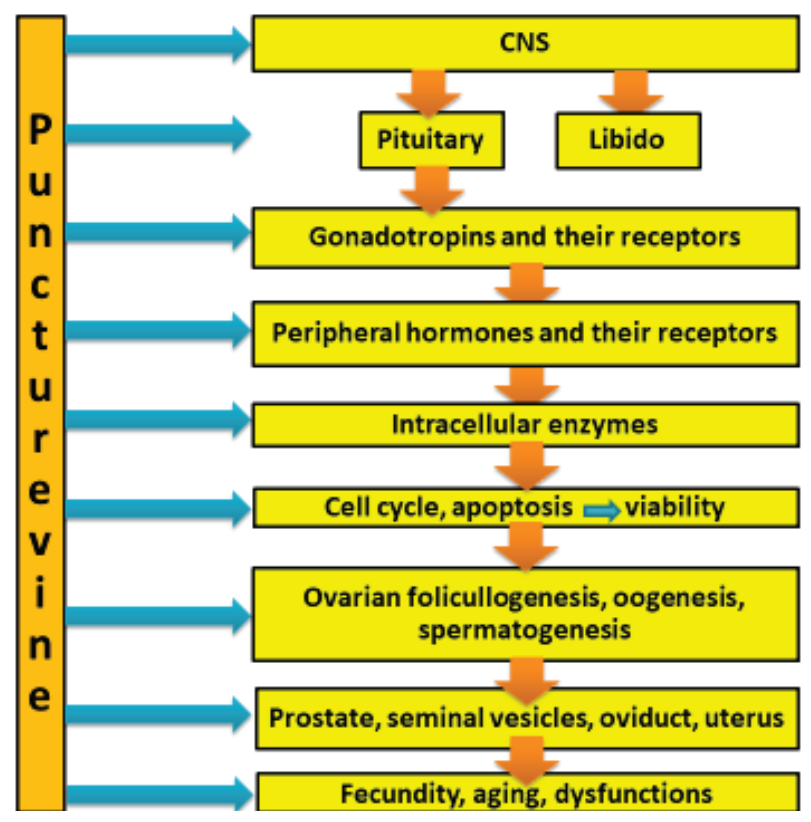

Fig. 1. The possible targets of puncturevine (Tribulus terrestris, L.) in male and female reproductive systems (simplified). The detailed explanations are in the text.

An in-vitro study showed the ability of Tribulus terrestris extract to promote accumulation of both proliferation and apoptosis markers in cultured porcine ovarian granulosa cells. The stimulatory action of puncture vine extract on both proliferation and apoptosis could indicate the ability of this plant to boost ovarian cell turnover. Furthermore, in these experiments, Tribulus terrestris prevented and even reversed the stimulatory action of metabolic hormone ghrelin on apoptosis marker (Sirotkin et al. 2020).

Experiments on rats with polycystic ovarian cysts (Dehghan et al. 2012) and with ovarian syndrome (PCOS) (Sandeep et al. 2015, Sayed et al. 2016), as well as on women with oligo/anovular infertility (Arentz et al. 2014) demonstrated the ability of Tribulus terrestris to induce their ovarian follicle development, ovulations, and fertility. Tribulus terrestris given together with Withania somnifera, prevented the signs of polycystic ovarian syndrome in rats - increase in estradiol and testosterone (but not in LH) release, increase in ovarian (but not uterus) weight and prolongation of the estrous cycle
(Sayed et al. 2016). Experiments of Dehghan et al. (2012) on rats demonstrated the applicability of Tribulus terrestris for luteinization and treatment of ovarian cysts.

Some animal studies demonstrated the ability of Tribulus terrestris extract to promote the development of uterine and vaginal tissue in rats (Esfandiari et al. 2011), but other studies did not show this action in rats (Martino-Andrade et al. 2010, Sayed et al. 2016) or women (Arentz et al. 2014).

Therefore, the available publications suggest the ability of Tribulus terrestris to promote female reproductive functions on various levels. It can promote female sexual desire, to alter release of pituitary gonadotropins and ovarian steroid hormones, BMP15 and GDF9, to promote ovarian cell proliferation and apoptosis, to promote ovarian cycle, development of uterus and vagina, ovulation and fecundity, as well as to mitigate the signs of PCOS and oligo/anovular infertility. Nevertheless, the available information concerning Tribulus terrestris action on animal ovary and uterus is conflicting. Furthermore, the ability of Tribulus terrestris to prevent signs of PCOS was more pronounced in animal experiments, than in clinical studies. The performed clinical trials were methodologically heterogenic, and they were performed on a relatively small number of patients, therefore they could not be considered as conclusive yet (Arentz et al. 2014).

\section{Mechanisms of effects on female reproduction}

There is evidence that Tribulus terrestris stimulates ovulation and fecundity and relieves symptoms of PCOS via promotion of release of pituitary and ovarian hormones - the known stimulators of reproductive processes. At least treatment of rats with Tribulus terrestris prevented the signs of induced PCOS - decrease in plasma FSH and increase in $\mathrm{LH}$, testosterone and estradiol level, increase in ovarian weight and decrease in weight of uterus (Sayed et al. 2016). Puncture vine treatment in women was associated with an increase in FSH and estradiol (which is characteristic for healthy women), but not of $\mathrm{LH}$ and testosterone (which is characteristic for women suffering from PCOS) (Arentz et al. 2014). Other studies however did not note a decrease, but increase in testosterone release in premenopausal women treated with Tribulus terrestris (Martimbianco et al. 2020).

The yeast androgen bioassay demonstrated that 
extract of Tribulus terrestris has an anti-androgen activity, whilst other plants (including Whithania somnifera) exhibited the androgenic properties (Sandeep et al. 2015). This anti-androgen action of puncture vine could explain its medicinal effect against PCOS assosiated with women androgenisation.

In contrast to animals, women's sexual desire is promoted by both estrogens and androgens, which activate sexual centers in CNS (Cappelletti and Wallen, 2016). The ability of Tribulus terrestris to promote women's sexual behavior can be explained by increased production of androgen (Martimbianco et al. 2020) and/or estrogen (Arentz et al. 2014). Estrogen, whose production can be boosted by puncture vine, is also a known regulator of ovarian cell proliferation and apoptosis, as well as a promoter of ovarian follicle development, survival and oogenesis (Sirotkin 2014). These processes can be promoted not only by estrogen, but also by BMP15 and GDF9 (Sanfins et al. 2018), whose expression in the ovary has been affected (mainly increased) by Tribulus terrestris (Abadieva et al. 2016).

Steroid hormones can regulate ovarian follicullogenesis and the resulting fecundity through an effect on ovarian cell proliferation and apoptosis. Their changes under direct influence of Tribulus terrestris, have been documented (Sirotkin et al. 2020). Therefore, steroid hormones might be considered as mediators of puncture vine action on ovarian state too.

The similarity of stimulatory action of Tribulus terrestris and estrogen on uterine and vaginal tissue's growth and development (Esfandiari et al. 2011) indicates that puncture vine contains phytoestrogens, activating estrogen receptors, which could be one of the possible mediators of Tribulus terrestris action on female reproductive system.

The involvement of other mechanisms in mediating puncture vine on female reproduction cannot be excluded either. It is very probable that brain structures, antioxidants a. o. can mediate Tribulus terrestris action not only on male (see above), but also on female reproduction.

The available data enables us to hypothesise several interrelated signaling pathways mediating Tribulus terrestris action on female reproductive functions and their disorders. They can include CNS structures, pituitary gonadotropins, steroid hormones, BMP15, GDF9 and their target processes including ovarian cell proliferation, apoptosis, ovarian follicullogenesis, oogenesis, ovulation and fecundity.
These hypothetical mechanisms of Tribulus terrestris action on female reproductive system are presented in Fig.1. The intervention of Tribulus terrestris to several regulatory pathways at once is highly probable.

\section{Application in reproductive biology and medicine}

The results of pre-clinical and clinical studies demonstrated the applicability of Tribulus terrestris for improvement of sperm quality and therefore of fertility in man and farm animals. It is not to be excluded that it could be useful also for promotion man's libido and erectile functions, although such application requires further validation yet.

The available information suggests that Tribulus terrestris could be a potent biostimulators of female reproductive processes - of sexual desire, ovarian cell turnover and follicular development, ovulation and fecundity. Its stimulatory influence on oogenesis, uterus and vagina growth are possible too (see Fig.1 for review), although this influence has not been verified on women. Furthermore, a limited number of clinical trials suggested that Tribulus terrestris can be successfully used for treatment of PCOS and related infertility.

\section{Conclusions and possible direction of future studies}

Analysis of the available publications demonstrated the influence of Tribulus terrestris on a wide spectrum of targets and physiological processes. This effect can be mediated by multiple extra- and intracellular signalling pathways. Some performed clinical studies demonstrated the applicability of this plant and its polyphenols for treatment of a number of various disorders according to the principles of traditional oriental and modern medicine. In particular, Tribulus terrestris can be a stimulator of male and female reproductive processes at the level of central nervous system, sexual behaviour, pituitary and gonadal hormones and their receptors, gonadal functions (including ovarian follicullogenesis and spermatogenesis), improvement of the quality and quantity of gametes (at least of sperm) and fecundity (Fig.1). This ability of puncture vine is applicable for improvement of man's sexual desire and sperm quality in vivo and in vitro, as well as of women's libido, activation in women reproductive organs, fecundity, and treatment 
of infertility, especially related to PCOS.

Nevertheless, understanding the biological role and application of puncture vine requires more profound studies. Although the main studies of this plant were aimed at its medical application, the physiological and medicinal effects of Tribulus terrestris were expressed better in animal experiments than in clinical trials, whose protocols and results are variable and therefore less conclusive. In the main cases, it remained unknown which plant constituent was responsible for a particular effect. Often the mediators of puncture vine effects have been only hypothesised on the basis of their changes after treatment with this plant, but their mediatory role remains to be demonstrated. A wide variety of possible factors mediating puncture vine effect on various targets and their possible interrelationships complicate understanding the mechanism of action of this plant and the causes of variability in its observed effects. Finally, the medicinal application of puncture vine requires more clinical tests on a larger number of patients with an adequate protocol and control groups. Nevertheless, the available data listed here demonstrate the biological and medicinal potency of this plant, the study and application of which is worth further efforts.

\section{Conflict of Interest}

There is no conflict of interest.

\section{Acknowledgements}

This work was supported by the Slovak Research and Development Agency (APVV) under the contract APVV15-0296, and by the Slovak Grant Agency of the Ministry of Education, Science and Sport and the Slovak Academy of Science, projects VEGA $1 / 0392 / 17$ and KEGA 033SPU-4/2021.

\section{References}

ABADJIEVA D, KISTANOVA E: Tribulus terrestris alters the expression of growth differentiation factor 9 and bone morphogenetic protein 15 in rabbit ovaries of mothers and f1 female offspring. PLoS One 11: e0150400, 2016. https://doi.org/10.1371/journal.pone.0150400

ABARIKWU SO, ONUAH CL, SINGH SK: Plants in the management of male infertility. Andrologia 52: e13509, 2020. https://doi.org/10.1111/and.13509

AL-BAYATI FA, AL-MOLA HF: Antibacterial and antifungal activities of different parts of Tribulus terrestris L. growing in Iraq. J Zhejiang Univ Sci B. 9: 154-159, 2008. https://doi.org/10.1631/jzus.B0720251

ARENTZ S, ABBOTT JA, SMITH CA, BENSOUSSAN A: Herbal medicine for the management of polycystic ovary syndrome (PCOS) and associated oligo/amenorrhoea and hyperandrogenism; a review of the laboratory evidence for effects with corroborative clinical findings. BMC Complement Altern Med 14: 511, 2014. https://doi.org/10.1186/1472-6882-14-511

ASADMOBINI A, BAKHTIARI M, KHALEGHI S, ESMAEILI F, MOSTAFAEI A: The effect of Tribulus terrestris extract on motility and viability of human sperms after cryopreservation. Cryobiology 75: 154-159, 2017. https://doi.org/10.1016/j.cryobiol.2017.02.005

BASAIYYE SS, NAOGHARE PK, KANOJIYA S, BAFANA A, ARRIGO P, KRISHNAMURTHI K, SIVANESAN S: Molecular mechanism of apoptosis induction in Jurkat E6-1 cells by Tribulus terrestris alkaloids extract. J Tradit Complement Med 8: 410-419, 2017. https://doi.org/10.1016/j.jtcme.2017.08.014

CAPPELLETTI M, WALLEN K: Increasing women's sexual desire: The comparative effectiveness of estrogens and androgens. Horm Behav 78:178-193, 2016. https://doi.org/10.1016/j.yhbeh.2015.11.003

CHEN Y, QUINN JC, WESTON LA, LOUKOPOULOS P: The aetiology, prevalence and morbidity of outbreaks of photosensitisation in livestock: A review. PLoS One. 14: e0211625, 2019. https://doi.org/10.1371/journal.pone.0211625

CHHATRE S, NESARI T, SOMANI G, KANCHAN D, SATHAYE S: Phytopharmacological overview of Tribulus terrestris. Pharmacogn Rev 8: 45-51, 2014. https://doi.org/10.4103/0973-7847.125530.

CLÉMENT C, WITSCHI U, KREUZER M: The potential influence of plant-based feed supplements on sperm quantity and quality in livestock: a review. Anim Reprod Sci 132: 1-10, 2012. https://doi.org/10.1016/j.anireprosci.2012.04.002 
DE SOUZA DB, BUYS-GONCALVES GF: Editorial Comment: Improvement of fertility parameters with Tribulus Terrestris and Anacyclus Pyrethrum treatment in male rats. Int Braz J Urol 45: 1055-1056, 2019. https://doi.org/10.1590/S1677-5538.IBJU.2018.0843.1

DEHGHAN A, ESFANDIARI A, BIGDELI SM: Alternative treatment of ovarian cysts with Tribulus terrestris extract: a rat model. Reprod Domest Anim 47: e12-5, 2012. https://doi.org/10.1111/j.1439-0531.2011.01877.x

ESFANDIARI A, DEHGHAN A, SHARIFI S, NAJAFI B, VESALI E: Effect of Tribulus terrestris extract on ovarian activity in immature Wistar rat: a histological evaluation. J Anim Vet Adv 10: 883-886, 2011.

GAMALEL DIN SF: Role of Tribulus terrestris in Male Infertility: Is It Real or Fiction? J Diet Suppl. 15: 1010-1013, 2018. https://doi.org/10.1080/19390211.2017.1402843

GAUTAM M, RAMANATHAN M: Saponins of Tribulus terrestris attenuated neuropathic pain induced with vincristine through central and peripheral mechanism. Inflammopharmacology 27: 761-772, 2019. https://doi.org/10.1007/s10787-018-0502-0

GAUTHAMAN K, ADAIKAN PG: Effect of Tribulus terrestris on nicotinamide adenine dinucleotide phosphatediaphorase activity and androgen receptors in rat brain. $\mathrm{J}$ Ethnopharmacol 96: 127-132, 2005. https://doi.org/10.1016/j.jep.2004.08.030

GHOSIAN MOGHADDAM MH, KHALILI M, MALEKI M, AHMAD ADABI ME: The effect of oral feeding of Tribulus terrestris L. on sex hormone and gonadotropin levels in addicted male rats. Int J Fertil Steril 7: 57-62, 2013.

HAGHMORAD D, MAHMOUDI MB, HAGHIGHI P, ALIDADIANI P, SHAHVAZIAN E, TAVASOLIAN P, HOSSEINI M, MAHMOUDI M: Improvement of fertility parameters with Tribulus Terrestris and Anacyclus Pyrethrum treatment in male rats. Int Braz J Urol 45: 1043-1054, 2019. https://doi.org/10.1590/S16775538.IBJU.2018.0843

HONG CH, HUR SK, OH OJ, KIM SS, NAM KA, LEE SK: Evaluation of natural products on inhibition of inducible cyclooxygenase (COX-2) and nitric oxide synthase (iNOS) in cultured mouse macrophage cells. J Ethnopharmacol 83: 153-159, 2002. https://doi.org/10.1016/s0378-8741(02)00205-2

KAMRANI RAD SZ, JAVADI B, HAYES AW, KARIMI G: Potential angiotensin converting enzyme (ACE) inhibitors from Iranian traditional plants described by Avicenna's Canon of Medicine. Avicenna J Phytomed 9: 291-309, 2019

KHALEGHI S, BAKHTIARI M, ASADMOBINI A, EMAEILI F: Tribulus terrestris extract improves human sperm parameters in vitro. J Evid Based Complementary Altern Med 22: 407-412, 2017. https://doi.org/10.1177/2156587216668110

KISTANOVA E, ZLATEV H, KARCHEVA V, KOLEV A: Effect of plant Tribulus terrestris extract on reproductive performances of rams. Biotechnol Anim Husb 21: 55-63, 2005

KUCHAKULLA M, NARASIMMAN M, SONI Y, LEONG JY, PATEL P, RAMASAMY R: A systematic review and evidence-based analysis of ingredients in popular male testosterone and erectile dysfunction supplements. Int $\mathrm{J}$ Impot Res 33: 311-317, 2021. https://doi.org/10.1038/s41443-020-0285-X

KUMARI M, SINGH P: Tribulus terrestris ameliorates metronidazole-induced spermatogenic inhibition and testicular oxidative stress in the laboratory mouse. Indian J Pharmacol 47: 304-310, 2015. https://doi.org/10.4103/02537613.157129

KUMARI M, SINGH P: Tribulus terrestris improves metronidazole-induced impaired fertility in the male mice. Afr Health Sci 8: 645-652, 2018. https://doi.org/10.4314/ahs.v18i3.22

MA Y, GUO Z, WANG X: Tribulus terrestris extracts alleviate muscle damage and promote anaerobic performance of trained male boxers and its mechanisms: Roles of androgen, IGF-1, and IGF binding protein-3. J Sport Health Sci 6: 474-481, 2017. https://doi.org/10.1016/j.jshs.2015.12.003

MARQUES MAA, LOURENCO BHLB, REIS MP, PAULI KB, SOARES AL, BELETTINI ST, DONADEL G, PALOZI RAC, FROEHLICH DL, LIVERO FADR, GASPAROTTO JUNIOR A, LOURENCO ELB: Osteoprotective Effects of Tribulus terrestris L.: Relationship Between Dehydroepiandrosterone Levels and $\mathrm{Ca}^{2+}$-Sparing Effect. J Med Food 22: 241-247, 2019. https://doi.org/10.1089/jmf.2018.0090 
MARTINBIANCO ALC, PACHECO RL, VILARINO FL, LATORRACA COC, TORLONI MR, RIERA R: Tribulus Terrestris for Female Sexual Dysfunction: A Systematic Review. Rev Bras Ginecol Obstet 42: 427-435, 2020. https://doi.org/10.1055/s-0040-1712123

MARTINO-ANDRADE AJ, MORAIS RN, SPERCOSKI KM, ROSSI SC, VECHI MF, GOLIN M, LOMBARDI NF, GRECA CS, DALSENTER PR: Effects of Tribulus terrestris on endocrine sensitive organs in male and female Wistar rats. J Ethnopharmacol 127: 165-170, 2010. https://doi.org/10.1016/j.jep.2009.09.031

MAZARO-COSTA R, ANDERSEN ML, HACHUL H, TUFIK S: Medicinal plants as alternative treatments for female sexual dysfunction: utopian vision or possible treatment in climacteric women? J Sex Med 7:3695-3714, 2010. https://doi.org/10.1111/j.1743-6109.2010.01987.x.

NEYCHEV VK, NIKOLOVA E, ZHELEV N, MITEV VI: Saponins from Tribulus terrestris L are less toxic for normal human fibroblasts than for many cancer lines: influence on apoptosis and proliferation. Exp Biol Med (Maywood). 232: 126-133, 2007.

NEYCHEV V, MITEV V: Pro-sexual and androgen enhancing effects of Tribulus terrestris L.: Fact or Fiction. J Ethnopharmacol 179: 345-355, 2016. https://doi.org/10.1016/j.jep.2015.12.055

PARAMA D, BORUAH M, YACHNA K, RANA V, BANIK K, HARSHA C, THAKUR KK, DUTTA U, ARYA A, MAO X, AHN KS, KUNNUMAKKARA AB: Diosgenin, a steroidal saponin, and its analogs: Effective therapies against different chronic diseases. Life Sci 260: 118182, 2020. https://doi.org/10.1016/j.lfs.2020.118182

PAHRAM S, KHARAZI AZ, BAKHSHESHI-RAD HR, NUR H, ISMAIL AF, SHARIF S, RAMAKRISHNA S, BERTO F: Antioxidant, Antimicrobial and Antiviral Properties of Herbal Materials. Antioxidants (Basel). 9: 1309, 2020. https://doi.org/10.3390/antiox9121309

POKRYWKA A, OBMIŇSKI Z, MALCZEWSKA-LENCZOWSKA J, FIJALEK Z, TUREK-LEPA E, GRUCZA R: Insights into Supplements with Tribulus Terrestris used by Athletes. J Hum Kinet 41: 99-105, 2014. https://doi.org/10.2478/hukin-2014-0037

RANJITHKUMAR R, ALHADIDI Q, SHAH ZA, RAMANATHAN M: Tribulusterine containing tribulus terrestris extract exhibited neuroprotection through attenuating stress kinases mediated inflammatory mechanism: in vitro and in vivo studies. Neurochem Res 44: 1228-1242, 2019. https://doi.org/10.1007/s11064-019-02768-7

RESHMA PL, BINU P, ANUPAMA N, VINEETHA RC, ABHILASH S, NAIR RH, RAGHU KG: Pretreatment of Tribulus terrestris L. causes anti-ischemic cardioprotection through MAPK mediated anti-apoptotic pathway in rat. Biomed Pharmacother 111: 1342-1352, 2019. https://doi.org/10.1016/j.biopha.2019.01.033

ROAIAH MF, ELKHAYAT YI, ABD El SALAM MA, DIN SFG: Prospective analysis on the effect of botanical medicine (tribulus terrestris) on serum testosterone level and semen parameters in males with unexplained infertility. J Diet Suppl 14: 25-31, 2017. https://doi.org/10.1080/19390211.2016.1188193

SAHIN K, ORHAN C, AKDEMIR F, TUZCU M, GENCOGLU H, SAHIN N, TURK G, YILMAZ I, OZERCAN IH, JUTURU V: Comparative evaluation of the sexual functions and NF- $\kappa$ B and Nrf2 pathways of some aphrodisiac herbal extracts in male rats. BMC Complement Altern Med 16: 318, 2016. https://doi.org/10.1186/s12906-016-1303-X

SAIYED A, JAHAN N, MAKBUL SAA, ANSARI M, BANO H, HABIB SH: Effect of combination of Withania somnifera Dunal and Tribulus terrestris Linn on letrozole induced polycystic ovarian syndrome in rats. Integr Med Res 5: 293-300, 2016. https://doi.org/10.1016/j.imr.2016.10.002

SALAHSHOOR MR, ABDOLMALEKI A, FARAMARZI A, JALILI C, SHIVA R: Does Tribulus terrestris improve toxic effect of Malathion on male reproductive parameters? J Pharm Bioallied Sci 12: 183-191, 2020. https://doi.org/10.4103/jpbs.JPBS 224_19

SALGADO RM, MARQUES-SILVA MH, GONCALVES E, MATHIAS AC, AGUITAR JG, WOLFF P: Effect of oral administration of Tribulus terrestris extract on semen quality and body fat index of infertile men. Andrologia 49, 2017. https://doi.org/10.1111/and.12655

SANAGOO S, SADEGHZADEH OSKOUEI B, GASSAB ABDOLLAHI N, SALEHI-POURMEHR H, HAZHIR N, FARSHBAF-KHALILI A: Effect of Tribulus terrestris L. on sperm parameters in men with idiopathic infertility: A systematic review. Complement Ther Med 42: 95-103, 2019. https://doi.org/10.1016/j.ctim.2018.09.015 
SANFINS A, RODRIGUES P, ALBERTINI DF: GDF-9 and BMP-15 direct the follicle symphony. J Assist Reprod Genet 35: 1741-1750, 2018. https://doi.org/10.1007/s10815-018-1268-4

SANTOS HO, HOWELL S, TEIXEIRA FJ: Beyond tribulus (Tribulus terrestris L.): The effects of phytotherapics on testosterone, sperm and prostate parameters. J Ethnopharmacol 235: 392-405, 2019. https://doi.org/10.1016/j.jep.2019.02.033

SANDEEP PM, BOVEE TF, SREEJith K: Anti-androgenic activity of nardostachys jatamansi DC and Tribulus terrestris L. and their beneficial effects on polycystic ovary syndrome-induced rat models. Metab Syndr Relat Disord 13: 248-254, 2015. https://doi.org/10.1089/met.2014.0136

SELLAMI M, SLIMENI O, POKRYWKA A, KIVAČIČ G, D HAYES L, MILIC M, PADULO J: Herbal medicine for sports: a review. J Int Soc Sports Nutr 15: 14, 2018. https://doi.org/10.1186/s12970-018-0218-y

SHAHEEN G, AKRAM M, JABEEN F, ALI SHAH SM, MUNIR N, DANIYAL M, RIAZ M, TAHIR IM, GHAURI AO, SULTANA S, ZAINAB R, KHAN M: Therapeutic potential of medicinal plants for the management of urinary tract infection: A systematic review. Clin Exp Pharmacol Physiol 46: 613-624, 2019. https://doi.org/10.1111/1440-1681.13092

SHAHID M, RIAZ M, TALPUR MM, PIRZADA T: Phytopharmacology of Tribulus terrestris. J Biol Regul Homeost Agents 30: 785-788, 2016.

SINGH B, SINGH JP, SINGH N, KAUR A: Saponins in pulses and their health promoting activities: A review. Food Chem 233: 540-549, 2017.

SIROTKIN AV, ALEXA R, HARRATH AH: Puncturevine (Tribulus terrestris L.) affects the proliferation, apoptosis, and ghrelin response of ovarian cells. Reprod Biol 20: $33-36,2020$. https://doi.org/10.1016/j.repbio.2019.12.009

ŠALAMON I, HABÁN M, BARANEC T, HABÁNOVÁ M, KNOLL M: The occurrence of puncture vine (Tribulus trerrestris) and its metabolic characteristics in Slovakia. Biologia (Bratislava) 61: 25-30, 2006. https://doi.org/10.2478/s11756-006-0004

UKANI MD, NANAVATI DD, MEHTA NK: A review on the ayurvedic herb tribulus terrestris L. Anc Sci Life 17: 144-150, 1997.

VERMA T, SINHA M, BANSAL N, YADAV SR, SHAH K, CHAULAN NS: (2020) Plants used as antihypertensive. 2021 11: 155-184, 2021. https://doi.org/10.1007/s13659-020-00281-x

WU Y, YANG H, WANG X: The function of androgen/androgen receptor and insulin growth factor-1/insulin growth factor-1 receptor on the effects of Tribulus terrestris extracts in rats undergoing high intensity exercise. Mol Med Rep 16: 2931-2938, 2017. https://doi.org/10.3892/mmr.2017.6891

YUAN Z, DU W, HE X, ZHANG D, HE W: Tribulus terrestris Ameliorates oxidative stress-induced ARPE-19 cell injury through the PI3K/Akt-Nrf2 signaling pathway. Oxid Med Cell Longev 2020: 7962393, 2020. https://doi.org/10.1155/2020/7962393

ZHU W, DU Y, MENG H, DONG Y, LI L: A review of traditional pharmacological uses, phytochemistry, and pharmacological activities of Tribulus terrestris. Chem Cent J 11: 60, 2017. https://doi.org/10.1186/s13065$\underline{017-0289-\mathrm{x}}$ 